\title{
Brain Structure in Preclinical Huntington's Disease: A Multi-Method Approach
}

\author{
Robert Christian Wolfa, b Philipp Arthur Thomann ${ }^{a}$ Anne Kerstin Thomann ${ }^{a}$ \\ Nenad Vasic ${ }^{b}$ Nadine Donata Wolf ${ }^{d} \quad$ G. Bernhard Landwehrmeyer ${ }^{c}$ \\ Michael Orth ${ }^{c}$ \\ ${ }^{a}$ Center of Psychosocial Medicine, Department of General Psychiatry, University of Heidelberg, Heidelberg, \\ Departments of ${ }^{\mathrm{b}}$ Psychiatry and Psychotherapy III and ${ }^{\mathrm{C}}$ Neurology, University of Ulm, Ulm, and ${ }^{\mathrm{d}}$ Central Institute of \\ Mental Health, Department of Addictive Behavior and Addiction Medicine, Mannheim, Germany
}

\section{Key Words}

Huntington's disease $\cdot$ Magnetic resonance imaging •

Voxel-based morphometry · Striatum · Cortex ·

Neuropsychology

\begin{abstract}
Background: Structural magnetic resonance imaging (MRI) of the brain could be a powerful tool for discovering early biomarkers in clinically presymptomatic carriers of the Huntington's disease gene mutation (preHD). So far, structural changes have been found mainly in preHD approaching the estimated motor onset of the disease (i.e. less than 15 years from onset), whereas structural findings in preHD far from the estimated motor onset have been inconclusive. Objectives: The aims of this study were to investigate the sensitivity of different methodological approaches to structural data in far-from-onset preHD (mean estimated time to motor onset $=21.4$ years) and to explore the relationship between brain structure, clinical variables and cognition. Methods: High-resolution MRI data at 3 T were obtained from 20 preHD individuals and 20 healthy participants and subsequent-
\end{abstract}

ly analyzed using voxel-based morphometry (VBM), cortical surface modeling and subcortical segmentation analysis techniques. Results: VBM analyses did not reveal significant between-group differences, whereas cortical surface modeling and subcortical segmentation analyses showed significant regional cortical thinning and striatal changes in preHD compared to controls. Significant correlations were found between striatal structure, estimated time to motor onset and executive performance, whereas cortical changes were not significantly correlated with these parameters. Conclusion: These data suggest that a combined methodological approach to structural MRI data could increase the sensitivity for detecting subtle neurobiological changes in early preHD. As consistently shown across different methods, the association between striatal structure and clinical measures supports the notion that changes in striatal volume could represent a more robust marker of disease progression than cortical changes.

Copyright $\odot 2012$ S. Karger AG, Basel

\section{KARGER}

Fax +4161306 1234

E-Mail karger@karger.ch

www.karger.com (c) 2012 S. Karger AG, Basel

$1660-2854 / 13 / 0121-0013 \$ 38.00 / 0$

Accessible online at:

www.karger.com/ndd
Robert Christian Wolf, MD

University of Heidelberg, Department of General Psychiatry

Vossstrasse 4

DE-69115 Heidelberg (Germany)

Tel. +4962215636601, E-Mail christian.wolf@med.uni-heidelberg.de 


\section{Introduction}

Huntington's disease (HD) is an autosomal dominant inherited neurodegenerative disorder caused by a CAG repeat expansion mutation in the HTT gene on chromosome 4 [1]. Clinically, the disease is characterized by progressive motor dysfunction, psychiatric disturbances and cognitive deficits. At present, much effort focuses on identifying therapeutic targets and developing treatments that may delay the onset of the disease, or slow down or stop the progression of HD once it manifests. Similarly important is the development of objective measures that allow reliable assessment of the effects on disease progression, or the prevention of the emergence of signs of HD in the preclinical phase (preHD), of such novel treatments. Magnetic resonance imaging (MRI) of brain structure in the preclinical period may be a powerful tool in this regard. Indeed, cross-sectional and longitudinal MRI studies have suggested that structural brain changes in carriers of the HD mutation may serve as biomarkers and potentially as surrogate endpoints in clinical trials [2-6]. However, intact brain structure in preHD has also been reported [7-10]. It is unlikely that these discrepancies can be solely explained by differing sample sizes, since clinical characteristics, such as the proximity to the onset of motor signs $[5,11,12]$, and different analysis procedures [13] may also account for data heterogeneity.

So far, several methods have been applied to the analysis of high-resolution MRI data; these include a priori regions-of-interest techniques [2], unbiased whole-brainbased methods such as voxel-based morphometry (VBM) $[7,8,14]$ and cortical thickness analyses $[9,15]$. Each of these approaches may offer particular methodological advantages; however, given the increasing number of imaging postprocessing software using different methodological algorithms, a considerable number of heterogeneous findings may also be attributed to the methods used to analyze the data. Nevertheless, methodologically complementary analyses of MRI data could also increase sensitivity for detecting early neural changes in preHD [7, 16]. Employing several different techniques in exploring the same structural data can therefore reveal a more comprehensive picture of very early neurobiological changes in preHD.

The aim of this study was to provide a comprehensive investigation of brain structure in preHD using different methodological approaches for the analysis of high-resolution structural MRI data. We chose to investigate a preHD sample with a mean time to the estimated motor onset of approximately 2 decades in order to identify poten-
Table 1. Demographics and clinical scores for healthy controls and preHD individuals

\begin{tabular}{llll}
\hline & $\begin{array}{l}\text { Controls } \\
(\mathrm{n}=20)\end{array}$ & $\begin{array}{l}\text { preHD } \\
(\mathrm{n}=20)\end{array}$ & $\begin{array}{l}\mathrm{p} \\
\text { value }\end{array}$ \\
\hline Age, years & $35.0 \pm 9.1$ & $36.0 \pm 8.8$ & 0.7 \\
Education, years & $15.3 \pm 3.0$ & $14.7 \pm 2.0$ & 0.4 \\
Gender (m/f) & $10 / 10$ & $10 / 10$ & \\
EHI score $^{\mathrm{a}}$ & $89.7 \pm 11.1$ & $85.2 \pm 14.4$ & 0.3 \\
CAG repeat length & n.a. & $42.1 \pm 3.0$ & \\
YTO & n.a. & $21.4 \pm 12.9$ & \\
YTO range, years & & $9-45$ & \\
UHDRS motor score & n.a. & $3.1 \pm 3.0$ & \\
UHDRS behavioral score & n.a. & $2.8 \pm 6.4$ & \\
UHDRS cognitive score & n.a. & $328.8 \pm 30.8$ & \\
\hline
\end{tabular}

Values represent mean \pm SD unless otherwise indicated. n.a. $=$ Not available in healthy participants; EHI $=$ Edinburgh Handedness Inventory; UHDRS = Unified Huntington's Disease Rating Scale.

a [63].

b Years to $60 \%$ probability of diagnostic onset [19].

tial structural changes in preHD at an early preclinical stage. To this end, we employed three well-established automated methods to analyze structural data obtained from healthy controls and far-from-onset preHD: (1) the VBM Diffeomorphic Anatomic Registration Through Exponentiated Lie Algebra algorithm (DARTEL); (2) the Oxford Centre for Functional MRI of the Brain's (FMRIB's) Integrated Registration and Segmentation Tool (FIRST), and (3) the FreeSurfer software package. We went on to examine the relationship between subcortical and cortical volume with genetic and clinical variables, such as CAG repeat length and the estimated time to motor onset considering the increasing subclinical and neurobiological changes which occur with closer proximity to the motor onset of the disease $[5,9,11,17,18]$. We finally administered a complementary neuropsychological test battery to relate structural changes to cognitive performance.

\section{Methods}

\section{Participants}

We studied 20 right-handed participants with a CAG repeat expansion $(\geq 39)$ in the huntingtin gene (table 1$)$ and a diagnostic confidence score of $\leq 2$ on the motor Unified Huntington's Disease Rating Scale [1]. All participants underwent a thorough neuropsychiatric examination including the complete Unified Hun- 
tington's Disease Rating Scale by clinicians with long-standing expertise in HD. PreHD participants with a history of another neurological disorder, a history of head trauma or learning disabilities were excluded from the study. In addition, all participants underwent a semistructured psychiatric interview in order to exclude axis I and axis II disorders according to DSM-IV-TR. The predicted time to the onset of motor symptoms (years to onset, YTO) was estimated with a probability of 0.6 using a formula based on age and CAG repeat length [19]. The healthy control group consisted of 20 right-handed participants matched for age, gender, education and handedness. Participants with a neurological or a psychiatric disorder according to DSM-IV-TR criteria, substance abuse or dependence were excluded. The local ethics committee approved the study (University of Ulm, Germany). Written informed consent was obtained from all participants following a complete description of the study's aims and procedures.

\section{Neuropsychological Assessment}

A neuropsychological test battery assessed various domains of frontostriatal function. This battery consisted of 7 tests, which assessed alertness, divided attention (DA), verbal and spatial working memory, executive function and inhibition processes. DA was measured using a computerized DA test from a standardized test battery [20] (http://www.psytest.net). Verbal and spatial working memory tests included the digit and spatial span (DS/SS), where both domains were tested forward and backward (12 verbal, or 9 spatial items, presented at $1 \mathrm{~Hz}$ ). Executive function was tested using a computerized version of the Wisconsin Card Sorting Test (WCST) [21]. This WCST variant consisted of 48 cards and a maximum of 5 category switches. Inhibition was tested by a computerized version of the Stroop Word-Color Interference Test [22] based on randomized single trials (20 trials per color and condition).

Performance measures were recorded as follows: (1) DA: mean reaction times (RT in milliseconds) of correctly identified targets as well as the absolute number of omitted targets (DA-om); (2) verbal span: number of correctly recalled digits in forward (DS-f) and backward (DS-b) direction; (3) SS: number of correctly recalled items in forward (SS-f) and backward (SS-b) direction; (4) WCST-P: number of perseverative errors (WCST-P), number of total errors (WCST-err) and adjusted switch costs following the procedure by Spitzer et al. [23] (WCST-sc in seconds), and (5) Stroop test: mean RT of correctly identified targets (Stroop-RT in milliseconds) as well as the difference of errors in the incongruent and congruent Stroop conditions (Stroop-Err).

\section{MRI Data Acquisition}

High-resolution structural data were acquired using a 3 Tesla Magnetom Allegra (Siemens, Erlangen, Germany) head MRI system. The MRI parameters of the three-dimensional magnetization-prepared rapid gradient-echo (3D-MPRAGE) sequence were as follows: $\mathrm{TE}=3.93 \mathrm{~ms} ; \mathrm{TR}=2,080 \mathrm{~ms} ; \mathrm{TI}=1,100 \mathrm{~ms} ; \mathrm{FOV}=256$ $\mathrm{mm}$; slice plane $=$ axial; slice thickness $=1 \mathrm{~mm}$; resolution $=1.0$ $\times 1.0 \times 1.0 \mathrm{~mm}^{3}$, and number of slices $=256$.

Data Analysis

Neuropsychological Assessment

Differences between controls and preHD individuals were assessed by calculating 11 separate $t$ tests (nominal level of alpha: $p<0.05)$. In order to avoid $\alpha$-error accumulation, all $t$ tests were Bonferroni-adjusted (corrected $\mathrm{p}<0.005$ ).

\section{MRI: Cortical Surface Modeling}

Cortical reconstruction was performed with the Freesurfer image analysis suite (Version 5.5.0, http://surfer.nmr.mgh.harvard.edu). The technical details of these procedures are described in prior publications [24-27]. Briefly, this processing includes removal of nonbrain tissue using a hybrid watershed/surface deformation procedure [27], automated Talairach transformation, intensity normalization [28], tessellation of the gray matter/white matter boundary, automated topology correction $[29,30]$, and surface deformation following intensity gradients to optimally place the gray/white and gray/cerebrospinal fluid borders at the location where the greatest shift in intensity defines the transition to the other tissue class [24]. Once the cortical models are complete, a number of deformable procedures can be performed for further data processing and analysis including surface inflation [25], registration to a spherical atlas which uses individual cortical folding patterns to match cortical geometry across subjects [26], parcellation of the cerebral cortex into units based on gyral and sulcal structure, and creation of a variety of surface-based data including maps of curvature and sulcal depth. This method uses both intensity and continuity information from the entire threedimensional MR volume in segmentation and deformation procedures to produce representations of cortical thickness, calculated as the closest distance from the gray/white boundary to the gray/cerebrospinal fluid boundary at each vertex on the tessellated surface [31]. The maps are created using spatial intensity gradients across tissue classes and are therefore not simply reliant on absolute signal intensity. In addition, the maps produced are not restricted to the voxel resolution of the original data and thus are capable of detecting submillimeter differences between groups.

Differences in cortical thickness between controls and preHD individuals were assessed with a vertex by vertex general linear model after smoothing the maps using a full width at half-maximum (FWHM) Gaussian kernel of $10 \mathrm{~mm}$. These analyses were corrected for multiple comparisons using a false discovery rate (FDR) of 0.05 [32]. Additional analyses in preHD participants examined the relationship between clinical variables (CAG repeat length and YTO), cognitive measures and thickness of the cortical mantle using a regression model ( $\mathrm{p}<0.001$, uncorrected). With regard to cognitive measures, we calculated correlations using DS-f and WCST-sc parameters only, because of a trend towards significant between-group differences (see also results section 'Neuropsychological assessment') and the well-described relevance of working memory and executive function in carriers of the HD gene mutation $[5,11,17,33,34]$.

\section{MRI: Subcortical Segmentation (SS)}

Automated segmentation of striatum, putamen and thalamus was performed using FSL FIRST as part of FMRIB's Software Library (FSL version 4.1, http://www.fmrib.ox.ac.uk/fsl/). Registration in FIRST comprises an affine transformation (12 degrees of freedom) of the original $\mathrm{T}_{1}$-weighted datasets to the MNI 152 standard space. After subcortical registration, a subcortical mask is applied in order to locate the different subcortical structures, followed by segmentation based on shape models and voxel intensities. The shape models used in FIRST are constructed from a 
library of hand-segmented $\mathrm{T}_{1}$ MRI datasets. The manual labels are parameterized as surface meshes and modeled as a point distribution model. Deformable surfaces are used to automatically parameterize the volumetric labels in form of meshes and are constrained to preserve vertex correspondence across the training data. The shape and appearance model is based on multivariate Gaussian assumptions with shape being expressed as a mean with modes of variation (principal components). Default options were used for boundary correction allowing determination of whether boundary voxels belong to the structure or not $(\mathrm{z}$ value $=3$, corresponding to a $99.998 \%$ certainty that the voxel belonged to the respective structure). A detailed description of FIRST can be found elsewhere [35].

Between-group vertex-wise shape differences were examined in the context of a general linear model analysis with entering each individual's SPM8-derived intracranial volume as a nuisance variable. Additional analyses in preHD participants examined the relationship between clinical/behavioral variables (CAG repeat length, YTO, DS-f, WCST-sc) and regional shape changes using a regression model ( $\mathrm{p}<0.001$, uncorrected).

\section{MRI: VBM}

Statistical Parametric Mapping software version 8 (SPM8; http://www.fil.ion.ucl.ac.uk/spm) running under Matlab version 7.9.0 (R2009b) was used for voxel-based analysis. After visually checking for artifacts, placing the origin on the anterior commissure, and classifying the $\mathrm{T}_{1}$-weighted scans into different tissue types via the segmentation routine in SPM8, the VBMDARTEL algorithm was applied in order to improve the registration of the MR images [36]. We followed Ashburner's study [36] in its standard version including an MNI 152 space transformation. The advantage of this optimized registration technique over the standard VBM approach - both in terms of localization and increased sensitivity - has been recently demonstrated [37, 38]. Briefly, the VBM-DARTEL algorithm uses a more sophisticated mathematical framework than the standard unified segmentation approach [39]. In VBM-DARTEL, deformations are produced by exponentiation of a velocity field, thus ensuring that the Jacobian determinants always remain positive. This precondition guarantees that the transformations are inversely consistent through generating both forward and inverse transformations from the same flow field. After preprocessing, the modulated normalized gray matter segments were smoothed using an 8-mm FWHM Gaussian kernel prior to the betweengroup analyses.

A one-way ANCOVA (diagnostic group as between-subject factor) was computed to compare whole-brain gray matter volumes treating intracranial volume (i.e. the sum of gray matter, white matter and cerebrospinal fluid as derived from the SPM8 segmentation) as a nuisance covariate. In order to control for the rate of false-positive results, whole-brain T maps were thresholded at $\mathrm{p}<0.05$, corrected for multiple comparisons (FDR correction over the whole brain as implemented in SPM8). In order to investigate the impact of different smoothing kernels on the VBM data [14], all between-group analyses were recalculated using data smoothed with 6 and $10 \mathrm{~mm}$, respectively. In preHD participants, regional correlations between local gray matter volume and clinical/behavioral variables (CAG repeat length, YTO, DS-f, and WCST-sc) were assessed by a voxel-wise regression analysis containing the results of each individual as explanatory and corre-
Table 2. Results of the neuropsychological assessment (two-sample $t$ tests, $\mathrm{p}<0.05$ )

\begin{tabular}{lccl}
\hline Test & $\begin{array}{l}\text { Controls } \\
(\mathrm{n}=20)\end{array}$ & $\begin{array}{l}\text { preHD } \\
(\mathrm{n}=20)\end{array}$ & $\begin{array}{l}\text { Uncorr. } \\
\text { p value }\end{array}$ \\
\hline DA, ms & $628.1 \pm 56.1$ & $650.5 \pm 72.3$ & 0.28 \\
DA-om & $1.0 \pm 1.0$ & $1.5 \pm 2.2$ & 0.26 \\
DS-f & $10.3 \pm 1.0$ & $9.4 \pm 1.5$ & $0.03^{\mathrm{a}}$ \\
DS-b & $8.9 \pm 1.8$ & $7.9 \pm 1.5$ & 0.14 \\
SS-f & $7.9 \pm 1.5$ & $8.5 \pm 2.2$ & 0.32 \\
SS-b & $7.7 \pm 2.0$ & $7.6 \pm 2.2$ & 0.93 \\
WCST-P & $0.7 \pm 1.4$ & $0.7 \pm 1.1$ & 1.00 \\
WCST-err & $2.6 \pm 2.0$ & $2.2 \pm 2.5$ & 0.58 \\
WCST-sc, s & $1.3 \pm 0.9$ & $2.0 \pm 1.1$ & $0.04^{\mathrm{a}}$ \\
Stroop-RT, ms & $66.7 \pm 53.4$ & $61.0 \pm 71.1$ & 0.78 \\
Stroop-err & $1.0 \pm 0.9$ & $1.4 \pm 1.5$ & 0.32 \\
\hline
\end{tabular}

See text for a detailed description of the cognitive tasks, the statistical analysis and significance levels. Values represent mean $\pm \mathrm{SD} . \mathrm{DA}=$ Divided attention; DA-om = divided attention, $\mathrm{ab}-$ solute number of omitted targets; $\mathrm{DS}-\mathrm{f}=$ digit span, forward condition; DS-b = digit span, backward condition; SS-f = spatial span, forward condition; SS-b = spatial span, backward condition; WCST-P = number of perseverative errors; WCST-err = number of total errors; WCST-sc = switch costs; Stroop-RT = Stroop effect/RT; Stroop-err = number of errors.

a This difference did not survive the Bonferroni correction for multiple comparisons.

sponding intracranial volumes as nuisance variables. Here, we applied a region-of-interest analysis for voxel within the striatum, globus pallidus, and thalamus, respectively, using ANSIR Laboratory's WFU PickAtlas (http://fmri.wfubmc.edu/software/PickAtlas) as anatomical reference. Within these masks, significance was set at a threshold of $\mathrm{p}<0.001$, uncorrected.

For all methods employed in this study, the output of each processing step was visually inspected for potential errors due to e.g. registration or segmentation. No manual editing was necessary.

\section{Results}

\section{Neuropsychological Assessment}

Compared with healthy controls, preHD participants showed a marginally lower verbal working memory span during the forward condition (DS-f) and higher switch costs during WCST performance (WCST-sc). However, these differences did not survive the correction for multiple comparisons. No group differences were found for the other cognitive measures (see table 2 for detailed results of the statistical analysis). 
Fig. 1. Cortical surface modeling analysis: regions showing reduced cortical thickness in preHD participants compared to healthy controls. Results of the 2 nd level between-group analysis ( $p<0.05$, FDRcorrected). The color bar represents the $\mathrm{T}$ value.
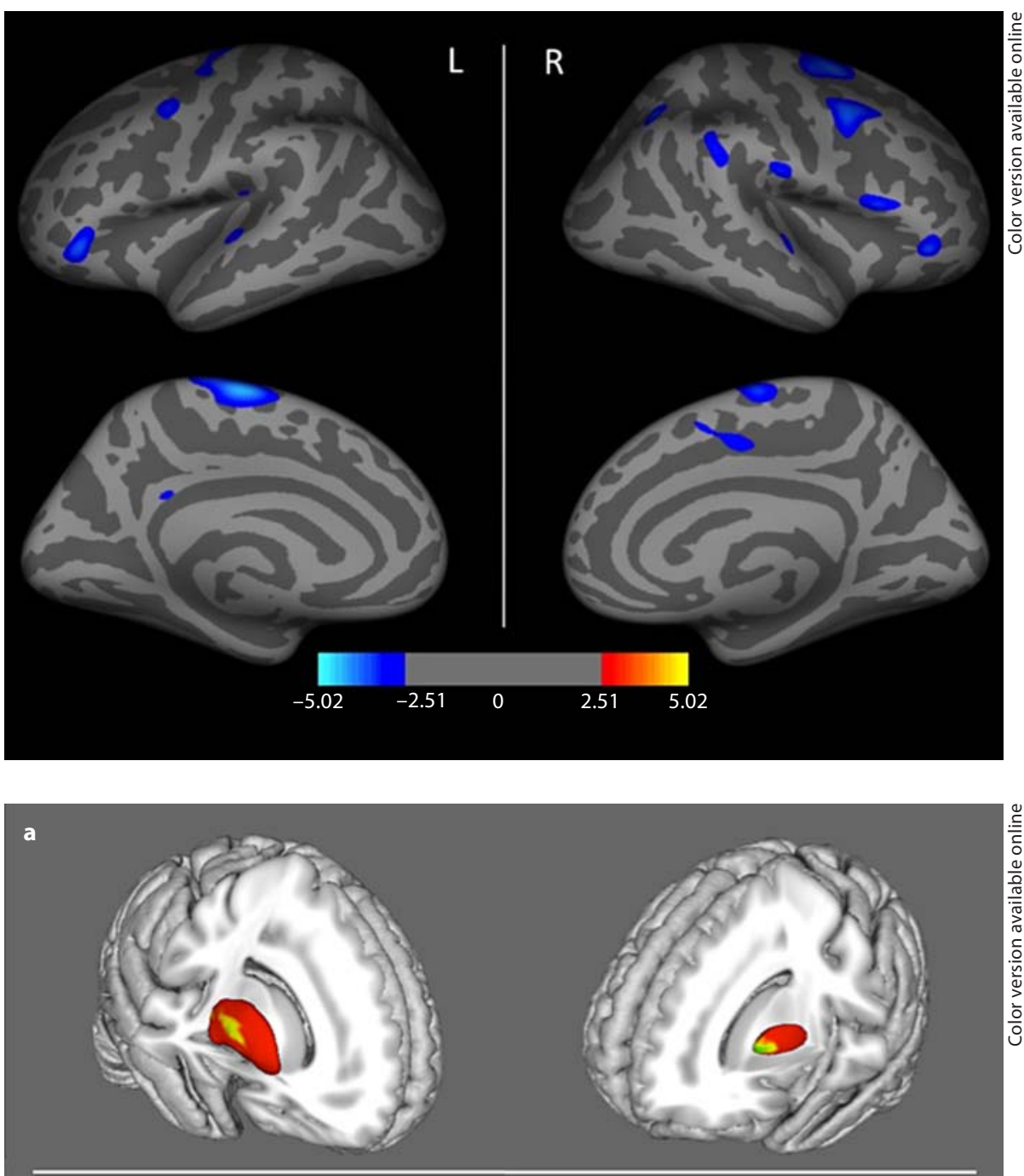

Fig. 2. Subcortical segmentation analysis. a Regions showing altered shape of the basal ganglia in the preHD group compared to controls. Results of the 2 nd level between-group analysis $(\mathrm{p}<0.001$, uncorrected). b Regions showing a positive correlation between the estimated YTO and subcortical shapes in the preHD group ( $p<0.001$, uncorrected). The color bar represents the $\mathrm{F}$ value.

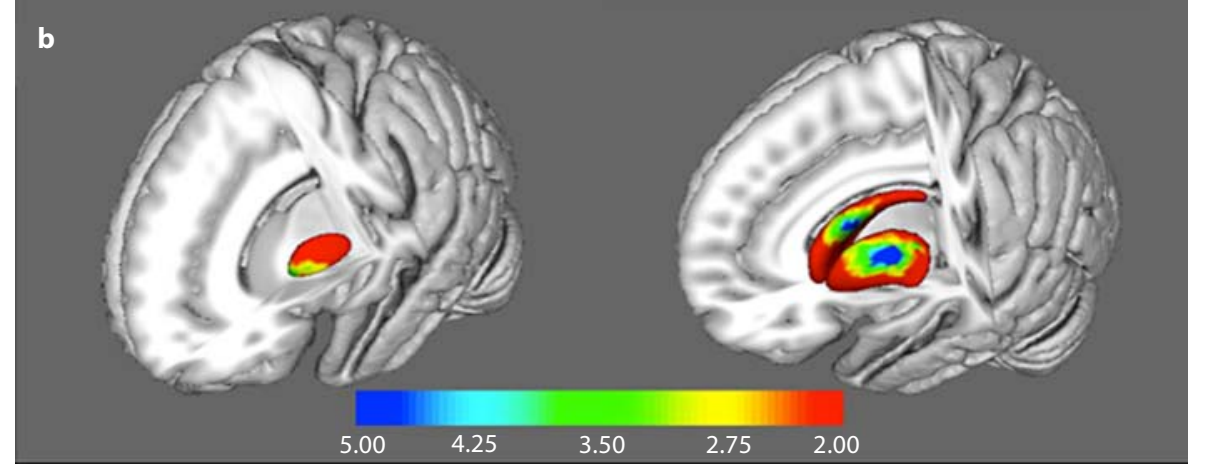

\section{MRI: Between-Group Comparisons}

Cortical Surface Modeling

Surface analyses revealed significant regional cortical thinning in preHD compared to healthy controls after correcting for multiple comparisons $(\mathrm{p}<0.05$, FDR-corrected). Regions showing reduced thickness included bi- lateral frontal and superior temporal areas. Cortical thinning was most prominent in the paracentral area, in the caudal middle frontal gyrus and the pars orbitalis and triangularis of the inferior frontal gyrus (fig. 1). There were no significant associations between clinical/behavioral parameters and cortical thickness in the preHD group. 


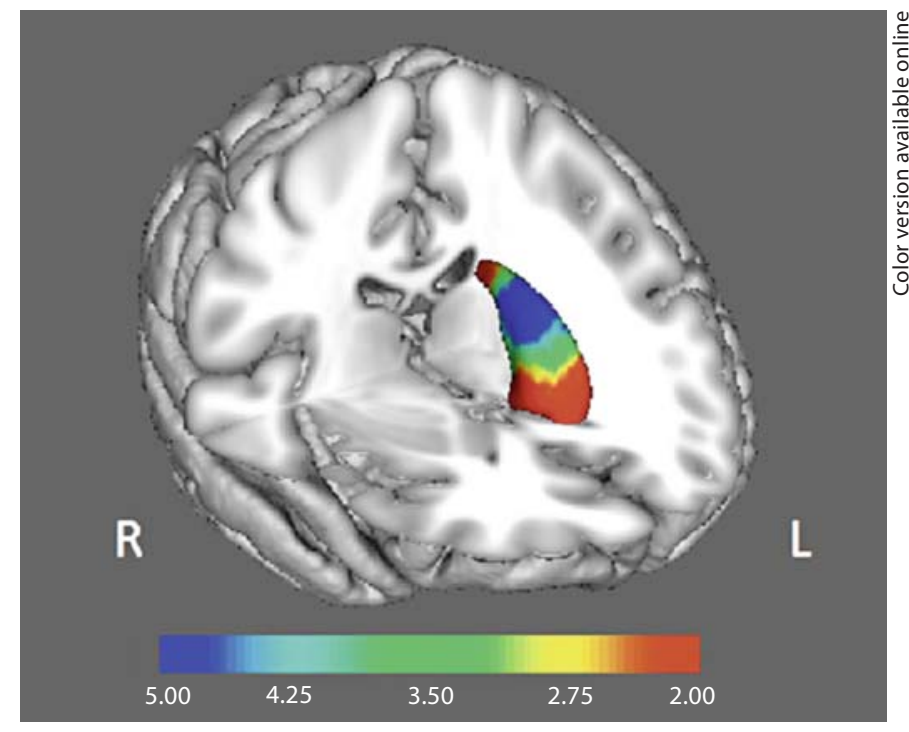

Fig. 3. Subcortical segmentation analysis: regions showing a positive correlation between switch costs during WCST performance and subcortical shapes in the preHD group $(\mathrm{p}<0.001$, uncorrected). The color bar represents the $\mathrm{F}$ value.

In order to address potential contributions of striatal volumes to cortical degeneration [15] we reanalyzed the cortical surface model in a complementary analysis. To this end, the between-group analysis was recalculated using the individual striatal volumes (caudate and putamen) as independent variables. However, this analysis did not change the results revealed by the first model.

\section{Subcortical Segmentation}

These analyses showed significant $(\mathrm{p}<0.001$, uncorrected) shape changes in the left pallidum and the right putamen in the preHD group compared to controls (fig. 2a; see also online supplementary table 1, www. karger.com/doi/10.1159/000338635, for details on subcortical volumes obtained by the FIRST segmentation procedure). In the preHD group, the nearer participants were to the estimated motor onset, the smaller the volumes of the left caudate, left putamen and left globus pallidus (fig. 2b). In addition, structural changes of the left caudate were associated with WCST switch costs, so that more pronounced shape changes were related to increased costs during card sorting (fig. 3).

\section{Voxel-Based Morphometry}

Significant between-group differences $(\mathrm{p}<0.05$, FDRcorrected) were not detected, regardless of the chosen smoothing kernel. These results remained stable using a threshold of $\mathrm{p}<0.001$, uncorrected. In the preHD group, proximity to the estimated motor onset was associated with reduced volume of the left caudate (fig. 4), so that the nearer a preHD participant was to motor onset, the smaller the volume of the caudate.

\section{Discussion}

This study employed three different methodological approaches to high-resolution structural data in farfrom-onset preHD. This revealed changes in striatal and extrastriatal regions in preHD using cortical surface modeling and subcortical segmentation analyses but not using the VBM-DARTEL approach. Striatal volume was smaller in preHD closer to the estimated motor onset, whereas cortical changes were not associated with clinical parameters.

Using VBM we did not detect differences between preHD and controls even though we used VBM-DARTEL, a methodologically more refined VBM analysis algorithm. Other VBM studies have shown volume loss in both striatal and 'extrastriatal' regions $[5,6,40]$; our VBM data are in line with negative findings from previous reports using a VBM approach [7, 13, 14]. Different sample sizes included in previous studies as well as methodological differences (such as 'modulated' vs. 'unmodulated' data $[13,41]$, size of the smoothing kernel, covariation for total intracranial volume or total gray matter volume or statistical thresholds) could at least partially explain this discrepancy. It is also possible that clinical characteristics, such as the estimated time to motor onset, could have contributed to negative findings. For instance, although in preHD less than 15 years from the estimated motor onset decreased striatal and cortical volume has been robustly detected using semiautomated analysis techniques $[5,9,11,42,43]$, several studies have suggested that in preHD far from the estimated motor onset there may be no such structural changes when studied cross-sectionally [7-9] nor substantial rates of change over time [14, 42]. We added to these reports in employing two additional techniques for structural analysis, cortical surface modeling and subcortical segmentation. Despite normal VBM-DARTEL results this approach revealed decreases of cortical thickness and striatal changes. Considering the anatomical topography of cortical thickness changes, our results are in good agreement with previous studies in preHD that reported reduced cortical thickness at least in individuals less than 15 years from the estimated motor onset $[5,9,15]$. In addition, the results of the subcorti- 
Fig. 4. VBM-DARTEL analysis: regions showing a positive correlation between the estimated YTO and brain volume in the preHD group ( $\mathrm{p}<0.001$, uncorrected). The color bar represents the $\mathrm{T}$ value.

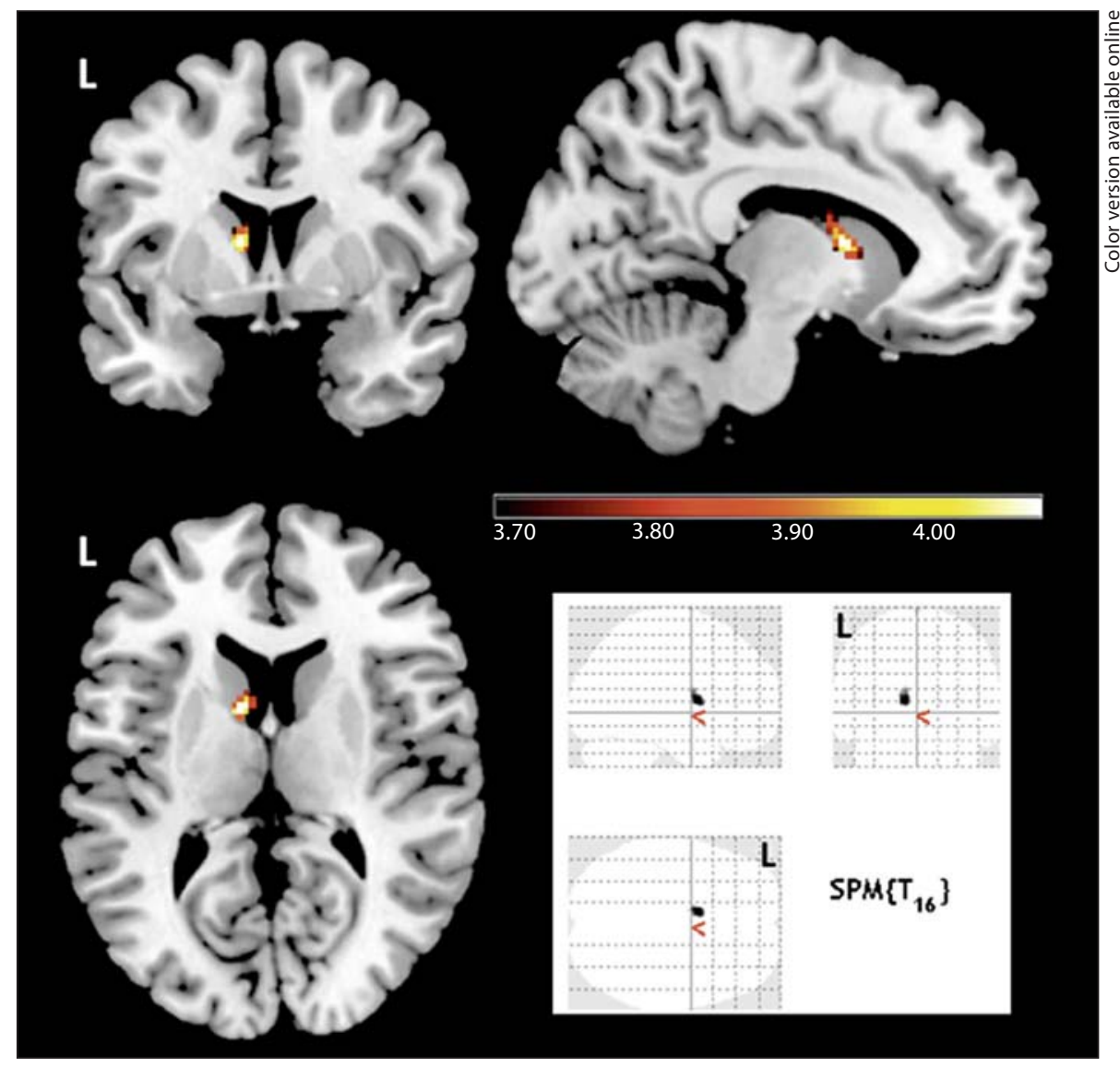

cal segmentation analysis are in accordance with the majority of structural studies reporting changes of striatal structures $[2,3,5,6]$.

The negative findings obtained by the VBM analyses are noteworthy, since VBM is a commonly used technique to assess brain structure in HD gene mutation carriers $[5,7,40,44,45]$. This raises the question whether a VBM approach to structural data in far-from-onset pre$\mathrm{HD}$ is less sensitive to change than measures of cortical thickness or subcortical shape models. In this regard, two factors may have to be considered. While automated whole-brain techniques have the advantage of assessing the entire brain, the segmentation and subsequent smoothing of smaller structures might affect spatial resolution and tissue contrast [14]. However, a smaller smoothing kernel of $6 \mathrm{~mm}$, or a larger smoothing kernel of 10 $\mathrm{mm}$, did not change the negative VBM results obtained with the initially chosen kernel of $8 \mathrm{~mm}$ FWHM. Thus, at least with regard to subcortical structures, the subcortical segmentation analysis may increase sensitivity to subtle subcortical changes in far-from-onset preHD.
Considering regional volume as the main output of a VBM analysis, it is important to note that volume is a function of thickness and regional surface, measures that could be differentially driven by biological factors [46]. In this regard, our data also confirm previous findings showing that volume loss in preHD is more related to cortical thinning than to changes of surface area [9]; therefore, cortical thinning may be detected in early preHD before concomitant changes of gray matter volume can be identified.

Our data further suggest that the estimated time to motor onset is associated with striatal volume but not with changes in cortical regions. This is consistent with previous reports indicating a particularly robust relationship between striatal structure and genetic load $[3,6,8$, $45,47]$ in contrast to cortical volume change $[6,45]$. Although derived from a cross-sectional study, our findings strongly suggest that striatal volume is a more sensitive indicator of disease-related changes over time than concomitant cortical changes. This notion is in accordance with longitudinal studies in preHD that reveal progres- 
sive volume loss in early preHD in the striatum only [48], while reduced cortical volumes at baseline do not substantially decline over time [42]. A lack of progressive cortical change in preHD as shown by most longitudinal studies so far is surprising given neuropathological evidence of higher concentrations of mutant huntingtin in cortical neurons [49-51] than in striatal regions. In addition, several studies reported widespread cortical thinning in preHD $[5,9,15]$ as well as functional changes of cortical regions in the absence of subcortical abnormalities $[7,10]$. Several explanations could account for the absent relationship between cortical changes and the estimated time to motor onset. It is possible that the speed of change differs between brain regions [52], so that changes in one brain region, in this case the striatum, and other regions such as the cortex may occur independently of one another $[8,15]$. This notion is also supported by our complementary analysis showing unchanged foci of cortical thickness when correcting for striatal volume. Alternatively, if there were no clear relationship between the estimated time to motor onset and cortical thickness, as found in our study, this could also imply that the difference between HD gene carriers and controls does not simply mirror the result of a dynamic pathological process, or the 'state', of HD. It may also reflect neurodevelopmental abnormalities [53], i.e. relatively stable neural effects of carrying the HD mutation irrespective of the estimated proximity to motor onset $[7,54,55]$.

In accordance with other reported cohorts [33, 56, 57], we found intact cognitive function in our preHD sample. Although only detected at a trend level, the findings of increased switch costs during WCST in preHD are nevertheless noteworthy. Switch costs have been used as time-dependent markers of cognitive flexibility during card sorting tasks [23], most likely measuring the functional integrity of frontostriatal circuits [58]. Recently, impaired WCST performance has been related to symptomatic 'conversion', where preHD individuals who developed overt signs of HD within approximately 8 years also demonstrated poorer WCST performance at baseline [33]. A similar finding has been previously reported for a longitudinally studied preHD cohort [59], suggesting the behavioral expression of frontostriatal dysfunction at least in preHD close to the estimated motor onset. Indeed, when relating striatal structure to measures of cognition, we found that more pronounced shape changes of the left caudate were also associated with increased switch costs during card sorting. These results suggest that subtle striatal changes may also relate to the level of cognitive function even though the overall cognitive per- formance in preHD does not significantly differ from controls. In this regard, our results are also in accordance with reports highlighting the relationship of frontostriatal function and executive performance in HD [60], and they are in line with computational models of corticostriatal function in neurodegenerative disorders [61].

We acknowledge several limitations of this study, such as the modest sample size and the cross-sectional design. It is worth noting that the methods used to calculate the probability of having first signs of $\mathrm{HD}$ are not precise [62]. While we do think that our participants are far from motor onset this means that the classification into near or far from onset can be inaccurate. Further, we cannot completely rule out the possibility that different findings of different MRI analysis tools might at least in part refer to the heterogeneity of data processing and statistical analysis procedures of the respective algorithms. In order to minimize statistical aspects as potential confounds, we strictly applied FDR correction for whole-brain and whole cortical mantle analyses and did not correct for multiple comparisons in case of clear neuroanatomically derived a priori hypotheses. Despite these potential constraints, however, the present data suggest that it is useful to consider different algorithms for the analysis of structural MRI data in preHD to increase the sensitivity of semiautomated whole-brain approaches. Although both cortical and striatal changes were detected by our analyses, an association between estimated time to motor onset, cognition and brain structure was only confirmed for striatal regions. Striatal volume may therefore represent a more robust marker of disease-related changes over time when contrasted to concomitant cortical changes. However, given the cross-sectional design of this study longitudinal studies are needed to confirm our findings.

\section{Acknowledgements}

R.C.W. was supported by a grant from the CHDI/High Q foundation, a non-for-profit organization dedicated to increase the understanding of HD and to facilitate the development of new treatment strategies for this illness (http://www.highqfoundation.org/). This study also received support from the European Huntington's Disease Network (EHDN, http://www.euro-hd.net/ html/network).

The authors would also like to thank all participants and their families for their time and interest in this study. We are grateful to Jürn Wolf and Johanna Fischer for their support with data collection. 


\section{References}

1 Huntington Study Group: Unified Huntington's Disease Rating Scale: reliability and consistency. Mov Disord 1996;11:136-142.

2 Aylward EH: Change in MRI striatal volumes as a biomarker in preclinical Huntington's disease. Brain Res Bull 2007;72:152158.

-3 Paulsen JS, Nopoulos PC, Aylward E, Ross CA, Johnson H, Magnotta VA, Juhl A, Pierson RK, Mills J, Langbehn D, Nance M: Striatal and white matter predictors of estimated diagnosis for Huntington disease. Brain Res Bull 2010;82:201-207.

-4 Paulsen JS, Magnotta VA, Mikos AE, Paulson HL, Penziner E, Andreasen NC, Nopoulos PC: Brain structure in preclinical Huntington's disease. Biol Psychiatry 2006;59: 57-63.

5 Tabrizi SJ, Langbehn DR, Leavitt BR, Roos RA, Durr A, Craufurd D, Kennard C, Hicks SL, Fox NC, Scahill RI, Borowsky B, Tobin AJ, Rosas HD, Johnson H, Reilmann R, Landwehrmeyer B, Stout JC: Biological and clinical manifestations of Huntington's disease in the longitudinal TRACK-HD study: cross-sectional analysis of baseline data. Lancet Neurol 2009;8:791-801.

-6 Stoffers D, Sheldon S, Kuperman JM, Goldstein J, Corey-Bloom J, Aron AR: Contrasting gray and white matter changes in preclinical Huntington disease: an MRI study. Neurology 2010;74:1208-1216.

7 Wolf RC, Vasic N, Schonfeldt-Lecuona C, Landwehrmeyer GB, Ecker D: Dorsolateral prefrontal cortex dysfunction in presymptomatic Huntington's disease: evidence from event-related fMRI. Brain 2007;130:28452857.

8 Henley SM, Wild EJ, Hobbs NZ, Scahill RI, Ridgway GR, Macmanus DG, Barker RA, Fox NC, Tabrizi SJ: Relationship between CAG repeat length and brain volume in premanifest and early Huntington's disease. J Neurol 2009;256:203-212.

-9 Nopoulos PC, Aylward EH, Ross CA, Johnson HJ, Magnotta VA, Juhl AR, Pierson RK, Mills J, Langbehn DR, Paulsen JS: Cerebral cortex structure in prodromal Huntington disease. Neurobiol Dis 2010;40:544-554.

-10 Zimbelman JL, Paulsen JS, Mikos AE, Reynolds NC, Hoffman RG, Rao SM: fMRI detection of early neural dysfunction in preclinical Huntington's disease. J Int Neuropsychol Soc 2007; 13:758-769.

- 11 Tabrizi SJ, Scahill RI, Durr A, Roos RA, Leavitt BR, Jones R, Landwehrmeyer GB, Fox NC, Johnson H, Hicks SL, Kennard C, Craufurd D, Frost C, Langbehn DR, Reilmann R, Stout JC: Biological and clinical changes in premanifest and early stage Huntington's disease in the TRACK-HD study: the 12-month longitudinal analysis. Lancet Neurol 2011;10:31-42.
12 Aylward EH, Sparks BF, Field KM, Yallapragada V, Shpritz BD, Rosenblatt A, Brandt J, Gourley LM, Liang K, Zhou H, Margolis RL, Ross CA: Onset and rate of striatal atrophy in preclinical Huntington disease. Neurology 2004;63:66-72.

13 Henley SM, Ridgway GR, Scahill RI, Kloppel S, Tabrizi SJ, Fox NC, Kassubek J: Pitfalls in the use of voxel-based morphometry as a biomarker: examples from Huntington disease. AJNR Am J Neuroradiol 2010;31:711-719.

14 Hobbs NZ, Henley SM, Ridgway GR, Wild EJ, Barker RA, Scahill RI, Barnes J, Fox NC, Tabrizi SJ: The progression of regional atrophy in premanifest and early Huntington's disease: a longitudinal voxel-based morphometry study. J Neurol Neurosurg Psychiatry 2010;81:756-763.

15 Rosas HD, Hevelone ND, Zaleta AK, Greve DN, Salat DH, Fischl B: Regional cortical thinning in preclinical Huntington disease and its relationship to cognition. Neurology 2005;65:745-747.

16 Wolf RC, Sambataro F, Vasic N, SchonfeldtLecuona C, Ecker D, Landwehrmeyer B: Aberrant connectivity of lateral prefrontal networks in presymptomatic Huntington's disease. Exp Neurol 2008;213:137-144.

17 Wolf RC, Sambataro F, Vasic N, SchonfeldtLecuona C, Ecker D, Landwehrmeyer B: Altered frontostriatal coupling in pre-manifest Huntington's disease: effects of increasing cognitive load. Eur J Neurol 2008;15:11801190.

18 Rupp J, Blekher T, Jackson J, Beristain X, Marshall J, Hui S, Wojcieszek J, Foroud T: Progression in prediagnostic Huntington disease. J Neurol Neurosurg Psychiatry 2009;81:379-384.

19 Langbehn DR, Brinkman RR, Falush D, Paulsen JS, Hayden MR, Group IHsDC: A new model for prediction of the age of onset and penetrance for Huntington's disease based on CAG length. Clin Genet 2004;65: 267-277.

20 Zimmermann P, Fimm B: Tests of Attentional Performance. Herzogenrath, Psytest, 1994.

21 Milner B: Effects of different brain lesions on card sorting. Arch Neurol 1963;9:90.

22 Perlstein WM, Carter CS, Barch DM, Baird JW: The Stroop task and attention deficits in schizophrenia: a critical evaluation of card and single-trial Stroop methodologies. Neuropsychology 1998;12:414-425.

23 Spitzer M, Franke B, Walter H, Buechler J, Wunderlich AP, Schwab M, Kovar K, Hermle L, Gron G: Enantio-selective cognitive and brain activation effects of N-ethyl-3,4-methylenedioxyamphetamine in humans. Neuropharmacology 2001;41:263-271.

24 Dale AM, Fischl B, Sereno MI: Cortical surface-based analysis. I. Segmentation and surface reconstruction. Neuroimage 1999;9: 179-194.
25 Fischl B, Sereno MI, Dale AM: Cortical surface-based analysis. II. Inflation, flattening, and a surface-based coordinate system. Neuroimage 1999;9:195-207.

26 Fischl B, Sereno MI, Tootell RB, Dale AM: High-resolution intersubject averaging and a coordinate system for the cortical surface. Hum Brain Mapp 1999;8:272-284.

27 Segonne F, Dale AM, Busa E, Glessner M, Salat D, Hahn HK, Fischl B: A hybrid approach to the skull stripping problem in MRI. Neuroimage 2004;22:1060-1075.

-28 Sled JG, Zijdenbos AP, Evans AC: A nonparametric method for automatic correction of intensity nonuniformity in MRI data. IEEE Trans Med Imaging 1998;17:87-97.

29 Fischl B, Liu A, Dale AM: Automated manifold surgery: constructing geometrically accurate and topologically correct models of the human cerebral cortex. IEEE Trans Med Imaging 2001;20:70-80.

30 Segonne F, Pacheco J, Fischl B: Geometrically accurate topology-correction of cortical surfaces using nonseparating loops. IEEE Trans Med Imaging 2007;26:518-529.

- 31 Fischl B, Dale AM: Measuring the thickness of the human cerebral cortex from magnetic resonance images. Proc Natl Acad Sci USA 2000;97:11050-11055.

32 Genovese CR, Lazar NA, Nichols T: Thresholding of statistical maps in functional neuroimaging using the false discovery rate. Neuroimage 2002;15:870-878.

- 33 Brandt J, Inscore AB, Ward J, Shpritz B, Rosenblatt A, Margolis RL, Ross CA: Neuropsychological deficits in Huntington's disease gene carriers and correlates of early 'conversion'. J Neuropsychiatry Clin Neurosci 2008;20:466-472.

34 Verny C, Allain P, Prudean A, Malinge MC, Gohier B, Scherer C, Bonneau D, Dubas F, Le Gall D: Cognitive changes in asymptomatic carriers of the Huntington disease mutation gene. Eur J Neurol 2007; 14:1344-1350.

35 Patenaude B: Bayesian Statistical Models of Shape and Appearance for Subcortical Brain Segmentation. Oxford, University of Oxford, 2007.

36 Ashburner J: A fast diffeomorphic image registration algorithm. Neuroimage 2007; 38:95-113.

37 Bergouignan L, Chupin M, Czechowska Y, Kinkingnehun S, Lemogne C, Le Bastard G, Lepage M, Garnero L, Colliot O, Fossati P: Can voxel based morphometry, manual segmentation and automated segmentation equally detect hippocampal volume differences in acute depression? Neuroimage 2009;45:29-37.

- 38 Yassa MA, Stark CE: A quantitative evaluation of cross-participant registration techniques for MRI studies of the medial temporal lobe. Neuroimage 2009;44:319-327. 
39 Ashburner J, Friston KJ: Unified segmentation. Neuroimage 2005;26:839-851.

-40 Thieben MJ, Duggins AJ, Good CD, Gomes L, Mahant N, Richards F, McCusker E, Frackowiak RS: The distribution of structural neuropathology in pre-clinical Huntington's disease. Brain 2002;125:1815-1828.

41 Good CD, Johnsrude IS, Ashburner J, Henson RN, Friston KJ, Frackowiak RS: A voxelbased morphometric study of ageing in 465 normal adult human brains. Neuroimage 2001;14:21-36.

-42 Kipps CM, Duggins AJ, Mahant N, Gomes L, Ashburner J, McCusker EA: Progression of structural neuropathology in preclinical Huntington's disease: a tensor based morphometry study. J Neurol Neurosurg Psychiatry 2005;76:650-655.

-43 Nopoulos P, Magnotta VA, Mikos A, Paulson $\mathrm{H}$, Andreasen NC, Paulsen JS: Morphology of the cerebral cortex in preclinical Huntington's disease. Am J Psychiatry 2007; 164: 1428-1434.

-44 Kassubek J, Juengling FD, Ecker D, Landwehrmeyer GB: Thalamic atrophy in Huntington's disease co-varies with cognitive performance: a morphometric MRI analysis. Cereb Cortex 2005;15:846-853.

45 Gomez-Anson B, Alegret M, Munoz E, Monte GC, Alayrach E, Sanchez A, Boada M, Tolosa E: Prefrontal cortex volume reduction on MRI in preclinical Huntington's disease relates to visuomotor performance and CAG number. Parkinsonism Relat Disord 2009; 15:213-219.

46 Winkler AM, Kochunov P, Blangero J, Almasy L, Zilles K, Fox PT, Duggirala R, Glahn DC: Cortical thickness or grey matter volume? The importance of selecting the phenotype for imaging genetics studies. Neuroimage 2009;53:1135-1146.
47 Ruocco HH, Bonilha L, Li ML, LopesCendes I, Cendes F: Longitudinal analysis of regional gray matter loss in Huntington disease: effects of the length of the expanded CAG repeat. J Neurol Neurosurg Psychiatry 2008;79:130-135.

48 Tabrizi SJ, Reilmann R, Roos RA, Durr A, Leavitt B, Owen G, Jones R, Johnson $\mathrm{H}$, Craufurd D, Hicks SL, Kennard C, Landwehrmeyer B, Stout JC, Borowsky B, Scahill RI, Frost C, Langbehn DR: Potential endpoints for clinical trials in premanifest and early Huntington's disease in the TRACKHD study: analysis of 24 month observational data. Lancet Neurol 2012;11:42-53.

49 Ferrante RJ, Gutekunst CA, Persichetti F, McNeil SM, Kowall NW, Gusella JF, MacDonald ME, Beal MF, Hersch SM: Heterogeneous topographic and cellular distribution of huntingtin expression in the normal human neostriatum. J Neurosci 1997;17:30523063.

50 Sapp E, Schwarz C, Chase K, Bhide PG, Young AB, Penney J, Vonsattel JP, Aronin N, DiFiglia M: Huntingtin localization in brains of normal and Huntington's disease patients. Ann Neurol 1997;42:604-612.

51 Gutekunst CA, Li SH, Yi H, Mulroy JS, Kuemmerle S, Jones R, Rye D, Ferrante RJ, Hersch SM, Li XJ: Nuclear and neuropil aggregates in Huntington's disease: relationship to neuropathology. J Neurosci 1999;19: 2522-2534.

52 Aylward EH, Nopoulos PC, Ross CA, Langbehn DR, Pierson RK, Mills JA, Johnson HJ, Magnotta VA, Juhl AR, Paulsen JS: Longitudinal change in regional brain volumes in prodromal Huntington disease. J Neurol Neurosurg Psychiatry 2011;82:405-410.

53 Nopoulos PC, Aylward EH, Ross CA, Mills JA, Langbehn DR, Johnson HJ, Magnotta VA, Pierson RK, Beglinger LJ, Nance MA, Barker RA, Paulsen JS: Smaller intracranial volume in prodromal Huntington's disease: evidence for abnormal neurodevelopment. Brain 2011;134:137-142.

54 Orth M, Schippling S, Schneider SA, Bhatia KP, Talelli P, Tabrizi SJ, Rothwell JC: Abnormal motor cortex plasticity in premanifest and very early manifest Huntington disease. J Neurol Neurosurg Psychiatry 2010;81:267270.
55 Schippling S, Schneider SA, Bhatia KP, Munchau A, Rothwell JC, Tabrizi SJ, Orth M: Abnormal motor cortex excitability in preclinical and very early Huntington's disease. Biol Psychiatry 2009;65:959-965.

56 Campodonico JR, Codori AM, Brandt J: Neuropsychological stability over two years in asymptomatic carriers of the Huntington's disease mutation. J Neurol Neurosurg Psychiatry 1996;61:621-624.

57 Brandt J, Shpritz B, Codori AM, Margolis R, Rosenblatt A: Neuropsychological manifestations of the genetic mutation for Huntington's disease in presymptomatic individuals. J Int Neuropsychol Soc 2002;8:918-924.

58 Monchi O, Petrides M, Petre V, Worsley K, Dagher A: Wisconsin Card Sorting revisited: distinct neural circuits participating in different stages of the task identified by eventrelated functional magnetic resonance imaging. J Neurosci 2001;21:7733-7741.

59 Snowden J, Craufurd D, Griffiths H, Thompson J, Neary D: Longitudinal evaluation of cognitive disorder in Huntington's disease. J Int Neuropsychol Soc 2001;7:33-44.

60 Hasselbalch SG, Oberg G, Sorensen SA, Andersen AR, Waldemar G, Schmidt JF, Fenger K, Paulson OB: Reduced regional cerebral blood flow in Huntington's disease studied by SPECT. J Neurol Neurosurg Psychiatry 1992;55:1018-1023.

61 Amos A: A computational model of information processing in the frontal cortex and basal ganglia. J Cogn Neurosci 2000;12:505519 .

62 Orth M, Schwenke C: Age-at-onset in Huntington disease. PLoS Currents: Huntington Disease, Version 65 2011, Jul 1 (revised 2011, Dec 21). http://knol.google.com/k/michaelorth/age-at-onset-in-huntington-disease/ 3dua5u7tnjalb/3.

63 Oldfield RC: The assessment and analysis of handedness: the Edinburgh inventory. Neuropsychologia 1971;9:97-113. 